\title{
Fatalities Resulting from Falls from Height in
}

\section{Agricultural Contexts}

\author{
Antonia Fanzutto \\ Department of Medical and Biological Sciences, Section of Forensic Medicine \\ University of Udine, Italy \\ Carlo Moreschi \\ Department of Medical and Biological Sciences, Section of Forensic Medicine \\ University of Udine, Italy

\section{Ugo Da Broi} \\ Department of Medical and Biological Sciences, Section of Forensic Medicine \\ University of Udine, Italy

\section{Gianfranco Pergher} \\ Department of Agriculture and Environmental Sciences (DISA) \\ University of Udine, Via delle Scienze 208, Udine, Italy

\section{Rino Gubiani} \\ Department of Agriculture and Environmental Sciences (DISA) \\ University of Udine, Via delle Scienze 208, Udine, Italy

\section{Michela Vello} \\ Department of Agriculture and Environmental Sciences (DISA) \\ University of Udine, Via delle Scienze 208, Udine, Italy

\section{Sirio Rossano Secondo Cividino} \\ Department of Agriculture and Environmental Sciences (DISA) \\ University of Udine, Via delle Scienze 208, Udine, Italy
}


Copyright (C) 2015 Antonia Fanzutto et al. This article is distributed under the Creative Commons Attribution License, which permits unrestricted use, distribution, and reproduction in any medium, provided the original work is properly cited.

\begin{abstract}
Agricultural work encompasses a variety of activities which carry with them different risks. One such activity is working at height, a frequent cause of fatal accidents. The aim of this work is to describe and discuss a typical case of a fall from height in order to understand the traumatic consequences of such accidents, to analyze the dynamics and lesions, and highlight the dangers of working at height. These falls, which may involve farm workers who are officially or unofficially employed, can produce injuries whose seriousness is not always strictly correlated to the height of the fall.
\end{abstract}

Keywords: Safety, Fall from height, Precipitating injuries, Agriculture, PPE

\title{
1 Introduction
}

Agricultural activities include a variety of working scenarios characterized by specific activities and risks connected with the use of tools, machinery, and exposure to inorganic chemicals and other toxic, biological substances [1-2].

The main areas of agricultural work are crop cultivation, animal breeding, and forestry (see Italian Civil Code, Codice Civile, art. 2135 comma 2). Agricultural workers can also be involved in performing other activities connected with the processing, conservation and marketing of the products obtained from farming and breeding.

The use of farm machinery and equipment to supply goods and services are also considered as agricultural work, together with the qualitative and ecological improvement of the natural environment and hospitality offered to tourists.

Collateral activities including the production of energy from biomass and the management of biogas plants are also considered to be agricultural [3-4].

All activities involved in agriculture carry with them a wide variety of risks, which concern not only farm workers who are legally employed in agricultural activities but also the farm owner's family and relatives who may be unofficially or informally involved.

The most frequent and serious risks involve the use of machinery (e.g. tractors and excavators), mechanical tools (e.g. chainsaws, grass trimmers and wood cutting machines), and chemical substances (e.g. pesticides and herbicides) and the handling and management of cattle and other large animals [5-6].

In detail, the risks are connected with: overturning machinery; hot parts of machinery; the use of cutting tools; working in conditions of noise and vibration; contact with biological agents such as dust and organic elements; the use of chemical agents such as ammonia and oxides; explosions; and animal handling. 
Another key element is that agricultural activities often involve working in solitude, often in open country or in isolated places like woods and forests.

A further factor to consider is that farm workers are often fairly elderly, especially in family-run businesses, and this brings with it an increased risk of pathologies associated with aging. In the analysis carried out by a workplace safety watchdog, from $1^{\text {st }}$ January 2011 to $31^{\text {st }}$ December 2013 there were 1515 fatal work-related accidents in Italy: 553 in 2011, 509 in 2012 and 453 in 2013 [7].

Of these, $36.5 \%$ occurred in the "agriculture, forestry, fishing and hunting" sector: 219 cases in 2011, 179 in 2012 and 208 in 2013.

In this sector the percentage of accidents involving workers aged $>65$ years was $42.5 \%$ in 2011 (93 cases), 43\% in 2012 (77 cases) and 48.6\% in 2013 (101 cases). The main cause of fatalities in this sector comes under the heading "the overturning of a vehicle / moving machinery" with 101 cases in 2011, 84 in 2012 and 124 in 2013. Of these the most frequent accident type involved a tractor overturning.

Other frequent causes of fatal accidents reported by the Watchdog are [7]:

- "Falling objects/crushing" (28 cases in 2011, 24 in 2012, 23 in 2013)

- "Being run over by agricultural vehicles" (16 cases in 2011, 10 in 2012, 16 in 2013)

- "Falling from height" ( 21 cases in 2011, 12 in 2012, 11 in 2013)

- "Contact with moving parts of machinery" (11 cases in 2011, 13 in 2012, 10 in 2013)

Falling from height therefore represents the third most frequent cause of fatal accidents in agricultural work in Italy. The dynamics of these accidents are related to "working at height" scenarios, which Italian law (Testo Unico 81/2008 artt. 105 and following) describes as any "working activities that expose workers to the risk of a fall from a height greater than 2 metres) onto a solid surface".

In farm work, there are many activities which come under this category, including pruning, fruit picking, building maintenance work, the installation of solar panels, and the use of large machinery (e.g. harvesters and farm tractors). Falling from height means that at some point the victim is in free fall, with no part of the body in contact with any supporting surfaces.

\section{Materials and methods}

This work was developed around two specific phases of statistical analysis: firstly, the study of post-mortem records in the Forensic Section of the Department of Medical and Biological Sciences of the University of Udine in order to evaluate the cases resulting from falls and secondly the description and examination of specific cases from agricultural contexts.

In the first phase the analysis focused on:

- dynamics and typology of the event (accidental or suicidal)

- height of the fall, sex and age of the victim and the cause of death, in workrelated accidents 
- identification of an exemplifying case from a farming context.

In the 22 years from 1993 to February 2015 there were 259 cases identified as "falls from height", of which:

- 141 cases were suicides

- 40 were accidental falls in the mountains

- 9 were ultralight plane crashes

A total of 24 cases of work-related falls from the period 1995 to 2014 were studied. Most of the victims were engaged in building (16 cases) and agricultural work ( 8 cases).

Another 20 cases from the period 1997 to 2014 were studied, and these fell into the "accidental fall from height" category, and included 6 cases of falls from trees, ladders, walls, barns, when the victim was involved in domestic or free-time activities rather than work. The second phase was based on the selection and discussion of cases which met the criteria of our study, namely that it should be a work-related accident involving a fall from height, where the victim was not using personal protective equipment (PPE), and where the workplace did not meet health and safety standards.

One case of a man who was an un-official worker restoring the roof of a stable destroyed by fire and who fell from a scaffold about 2.80 metres high, was chosen as an exemplifying case study.

Medico-legal analysis of the risks, the forces developed in falling from height, and the resistance of the human body (and in particular the head) to various types of impact trauma, was performed through analysis of the wounds and the dynamics of the accident.

\section{Results}

The archives of the above-mentioned Forensic Section contain records of 24 workplace deaths caused by falls from height, which were followed by external examination or autopsy, between January 1995 and December 2014.

All the workers were male, and their ages ranged from 26 to 72 years old.

Figure 1 shows the distribution of accidents by age group.

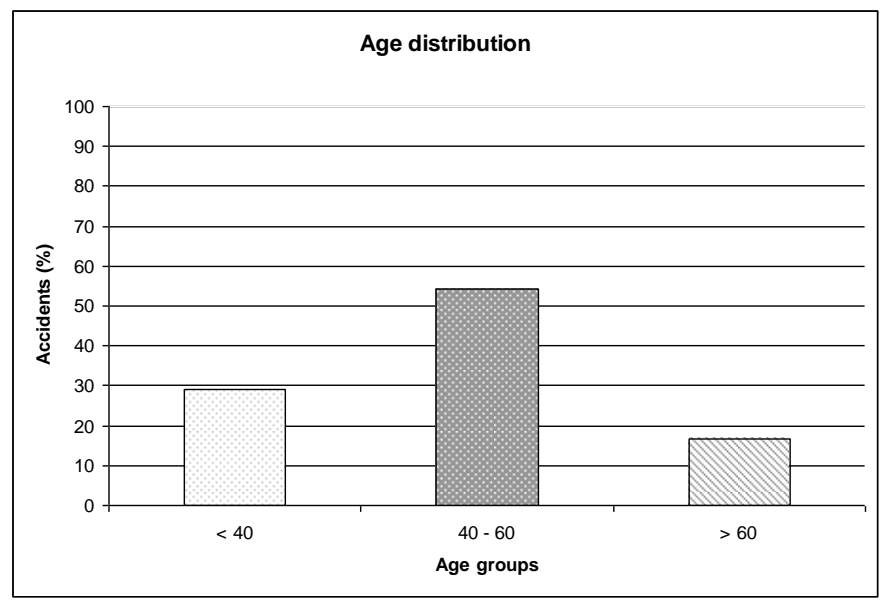

Figure 1 - Distribution of accidents by age group (\%) 
The falls occurred from a height of between 2.50 and 30 metres, with one-third of the cases involving heights lower than 4 metres. The distribution of accidents in relation to height from the ground is shown in Figure 2.

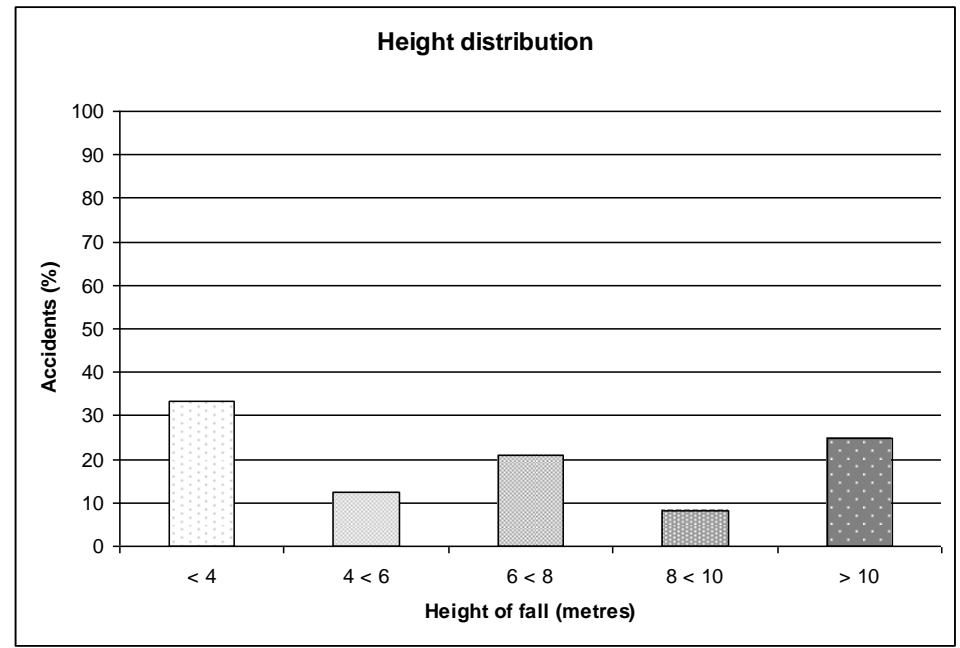

Figure 2 - Distribution of accidents by height from the ground (\%)

To understand why falls can be fatal even when the height involved is not great, it is necessary to focus on injury patterns [8]. In most cases, cranial and cerebral structures are involved; the skull is not very resistant to impact because it does not deform to any significant degree. Moreover, the brain has no mobility inside the skull, which means that it is not able to absorb energy, even when the forces involved are not great.

When the corpse is examined externally, it is often possible to identify a "point of impact", which means an anatomical area where lesions are concentrated and which represents the point of initial impact of the body with the ground.

Sometimes, in the free fall phase, the body may bump against other structures; in these cases, there may be multiple lesions located in different anatomical regions.

Figure 3 shows the distribution of lesions in the 24 cases. 


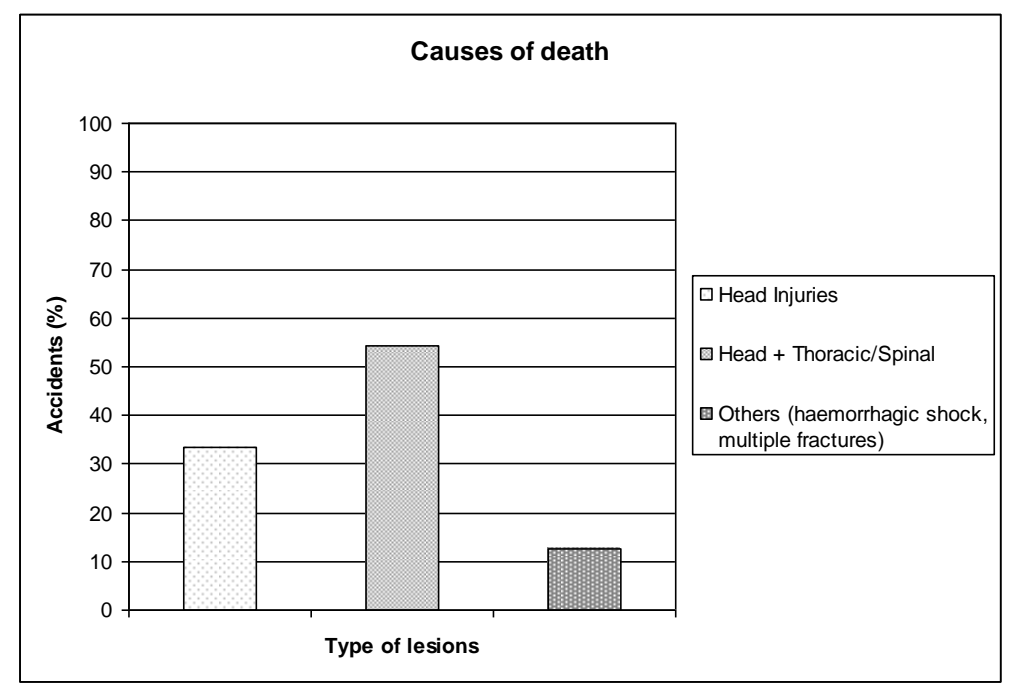

Figure 3 - Anatomical distribution of causes of death

In deaths caused by falls from height, there is often a characteristic disproportion between external lesions (bruising, abrasions, lacerations and compound fractures) and internal lesions, which are widespread and more serious.

The internal lesions are sometimes attributable to the impact with the ground but more often are caused by the violent deceleration involved, because, while the body stops moving suddenly, some internal organs do not. In support of this explanation, autopsies often reveal haemorrhaging due to the laceration of blood vessels, and the detachment of the heart from the large vessels and of the lungs from the hili.

Furthermore, the viscera may be forced against the walls of cavities, causing contusions at the base of the brain or ruptures and lacerations of the parenchyma of some organs such as the liver and spleen, both due to the direct transmission of the force and also to a recoil mechanism [9].

In some cases, falling from height causes sudden death, or survival for a few minutes or hours before death [10].

When a patient is admitted to hospital for major trauma, surgical treatment may be necessary, but the health and physical condition of the patient can render this extremely complicated, with death in any case ensuing a few hours or days after the traumatic event. Such complications include respiratory infections, pulmonary embolism, and acute heart failure, with the added complication of existing heart issues in elderly farm workers [11], [23].

Another possible cause of delayed death is the onset of a post-traumatic intra-cranial haematoma, such as a subdural haematoma resulting from the rupture of the bridging veins on the surface of the brain; this lesion can be sub-acute or chronic and it can appear suddenly after a period of apparent patient stability [12]. 


\section{Case study}

B. F., a 50 year-old man, was working with a male colleague on the renovation of the roof of a cowshed.

At the moment the accident occurred, he was working alone.

He was found at the foot of a low scaffold tower on the upper floor.

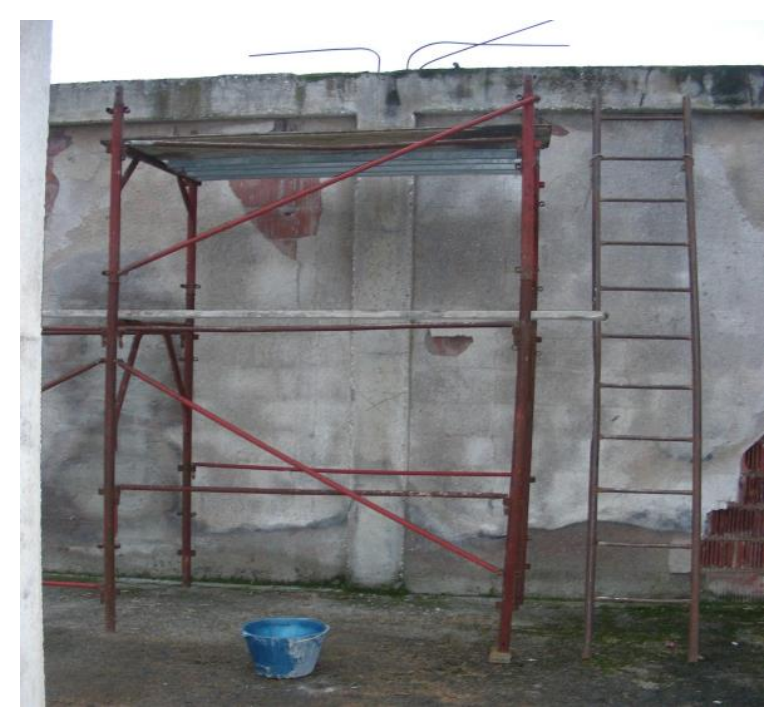

Photo 1 - Work place and scaffold

Photo 1 shows the scaffold: the structure was not anchored and had no parapet; the planking was incomplete and was composed of a mixture of metal decking and wooden boards and was partially reinforced with a wooden pole.

The victim was working on a platform about 2.80 metres above the floor.

On inspection, it was found that the man, who was lying dead on the concrete floor, had not been wearing a hard hat and had no harness.

External examination of the body and subsequent autopsy were performed.

The external lesions observed were: rhinorrhagia, swollen cranial tissue in the left parietal-occipital area; oedema in left orbit tissue with bruising and hyperaemia of the conjunctivae; there were also some abrasions on the right hand and right thigh, less than 10 millimetres across.

The internal lesions were as follows: haematic infiltration of the soft tissue of the left frontal and parietal region; fractures of the skull involving the left parietal bone, the left temporal bone, the left sphenoid wing, the left medium fossa and the the sella turcica; bilateral parietal subarachnoid haemorrhage and haemorrhage in the cerebellum; blood in ventricles; micro-haemorrhages in the brain stem; haematic infiltration of the vertebral muscles in the cervical and upper thoracic region; pulmonary contusions; rib fractures resulting from cardiopulmonary resuscitation. 
The cause of death was ascribed to cranial and cerebral lesions.

In falls from height, head injuries normally involve impact with a flat surface, and indeed the point of impact in this case can be found in the left parietal-occipital area, where the soft tissue was swollen and the fractures lines started.

Rhinorrhage, left orbit bruising and subconjunctival bleeding suggest that blood seeped through the fracture lines in the cranial basis.

Bilateral subarachnoid haemorrhaging can be linked with a recoil mechanism, which leads to a rupturing of the blood vessels due to the transmission of the force of impact inside the stiff and narrow structure of the cranium [13].

Haematic infiltration of the vertebral muscles in the cervical and upper thoracic region and pulmonary contusions are the result of a thoracic trauma, with the victim's clothes ensuring that there were no external signs; by analyzing the lesions, it would appear that the victim fell backwards onto a flat surface.

\section{Conclusions and perspectives}

Falls from height in agricultural contexts involve both regular farm workers and family members working on a more informal basis, and also unofficial workers, and are a frequent cause of injury, sometimes fatal. [19] [21].

Generally, the most frequent scenarios involve falls from ladders, scaffolding, and the roofs of agricultural buildings such as stables and barns.

These accidents may happen because people underestimate the risks involved, and are careless when working at height. [14] [15] [21].

Other factors that increase the level of risk and worsen the consequences of an accident are that farm work is often carried out in isolated places, without any chance of prompt medical intervention, and the fact that there may be concomitant pathologies, particularly in elderly subjects.

Head injuries are the main cause of death, both when death is immediate and when it occurs subsequently; the impact of lesions involving other anatomical areas (e.g. thoracic trauma, haemorrhaging due to vascular trauma, spinal trauma, and trauma of the abdominal viscera) are dependent on the speed with which medical support can be provided, which means that working alone and in isolated areas increases the risk of death.

To avoid a fatal outcome, in particular in head injuries, it is necessary to decrease the effects of the force of impact in the following three main ways:

1) By installing collective protective systems, such as permanent or temporary guardrails, scissor lifts and fixed scaffold towers

2) By using personal protective equipment, such as safety harnesses, energy-absorbing lanyards and safety helmets, in order to absorb the force of impact [14] 
3) By adopting the correct procedures both in the working and in the domestic environment (in the case study there was no awareness of safe working procedures)

In conclusion the importance of raising awareness of safe working procedures in agricultural, as well as domestic, environments cannot be overstressed.

Technical research into the dynamics and traumatic consequences of accidents are of fundamental importance if we are to prevent their occurrence and lessen their impact, by promoting awareness of health and safety issues against a background of ongoing research and improvement.

\section{References}

[1] G. Pergher, R. Gubiani, S.R.S. Cividino, D. Dell'Antonia, C. Lagazio, Assessment of spray deposition and recycling rate in the vineyard from a new type of air-assisted tunnel sprayer, Crop Protection, 45 (2013), 6 - 14. http://dx.doi.org/10.1016/j.cropro.2012.11.021

[2] B. Gaspardo, S. Del Zotto, E.A. Torelli, S.R.S. Cividino, G. Firrao, G.D. Della Riccia, B.A. Stefanon, A rapid method for detection of fumonisins B1 and B2 in corn meal using Fourier transform near infrared (FT-NIR) spectroscopy implemented with integrating sphere, Food Chemistry, 135 (2012), no 3, 1608 - 1612. http://dx.doi.org/10.1016/j.foodchem.2012.06.078

[3] D. Dell'Antonia, G. Pergher, S.R.S. Cividino, R. Gubiani, M. Cecchini, A.B. Marucci, Characterization of biomass emissions and potential reduction in small-scale pellet boiler, Computational Science and Its Applications ICCSA 2013, 13th International Conference, Ho Chi Minh City, Vietnam, June 24/27, 2013, Proceedings, Part II, of the series Lecture Notes in Computer Science, 7972 (2013), 192 - 206.

http://dx.doi.org/10.1007/978-3-642-39643-4_15

[4] S.R.S. Cividino, O. Malev, M. Lacovig, G. Pergher, D. Dell'Antonia, R. Gubiani, M. Vello, BiogasAgriAtex, new methods of risk assessment explosion on biogas plants, Applied Mathematical Sciences, 8 (2014), no. 132, 6599 - 6619. http://dx.doi.org/10.12988/ams.2014.46449

[5] C. Moreschi, U. Da Broi, S. Cividino, R. Gubiani, G. Pergher, Neck injury patterns resulting from the use of petrol and electric chainsaws in suicides. Report on two cases, Journal of Forensic and Legal Medicine, 25 (2014), 14 - 20. http://dx.doi.org/10.1016/j.jflm.2014.04.004 
[6] G. Pergher, N. Zucchiatti, R. Gubiani, Influence of spray application parameters on deposition in an asparagus crop, Journal of Agricultural Engineering Research, 73 (1999), on. 1, 19 - 28.

http://dx.doi.org/10.1006/jaer.1998.0386

[7] Vega Engineering s.r.l. Osservatorio Sicurezza sul Lavoro, Rapporto morti bianche triennio 2011/12/13 - 18/01/2014.

[8] J. Con, R.S. Friese, D.M. Long, B. Zangbar, T. O’Keeffe, B. Joseph, P. Rhee, A.L. Tang, Falls from ladders: age matters more than height, Journal of Surgical Research, 191 (2014), 262 - 267.

http://dx.doi.org/10.1016/j.jss.2014.05.072

[9] M.B. Casali, A. Battistini, A. Blandino, C. Cattaneo, The injury pattern in fatal suicidal falls from a height: An examination of 307 cases, Forensic Science International, 244 (2014), 57 - 62.

http://dx.doi.org/10.1016/j.forsciint.2014.08.004

[10] S. Arbes, A. Berzlanovich, Injury pattern in correlation with the height of fatal falls, Wiener klinische Wochenschrift, 127 (2015), no. 1-2, 57 - 61.

http://dx.doi.org/10.1007/s00508-014-0639-9

[11] T. Topp, T. Muller, I. Kiriazidis, R. Lefering, S. Ruchholtz, C.A. Kühne, Multiple blunt trauma after suicidal attempt: An analysis of 4,754 multiple severely injured patients, European Journal of Trauma and Emergency Surgery, 38 (2012), no. 1, 19 - 24.

http://dx.doi.org/10.1007/s00068-011-0114-5

[12] L.R. Mack, S.B. Chan, J.C. Silva, T.M. Hogan, The use of head computed tomography in elderly patients sustaining minor head trauma, The Journal of Emergency Medicine, 24 (2003), no. 2, 157 - 162.

http://dx.doi.org/10.1016/s0736-4679(02)00714-x

[13] N. Yoganandan, F.A. Pintar, Biomechanics of temporo-parietal skull fracture, Clinical Biomechanics Volume, 19 (2004), no. 3, 225 - 239.

http://dx.doi.org/10.1016/j.clinbiomech.2003.12.014

[14] D.J.M. Macdonald, K.A. Sanati, E.B. Macdonald, The Costs and Characteristics of Occupational Injuries Admitted to a Trauma Unit, International Journal of Occupational Safety and Ergonomics, 18 (2012), no. 4, 587-590. http://dx.doi.org/10.1080/10803548.2012.11076961 
[15] M. Cecchini, F. Cossio, A. Marucci, D. Monarca, A. Colantoni, M. Petrelli, E. Allegrini, Survey on the status of enforcement of European directives on health and safety at work in some Italian farms, Journal of Food, Agriculture and Environment, 11 (2013), no. 3\&4, 595 - 600.

[16] D. Monarca, M. Cecchini, A. Colantoni, G. Menghini, R. Moscetti, R. Massantini, The evolution of the chestnut harvesting technique, Acta Horticulturae 1043: II European Congress on Chestnut, (2014), 219 - 224. http://dx.doi.org/10.17660/actahortic.2014.1043.29

[17] D. Monarca, R. Moscetti, L. Carletti, M. Cecchini, A. Colantoni, E. Stella, G. Menghini, S. Speranza, R. Massantini, M. Contini, A. Manzo, Quality maintenance and storability of chestnuts manually and mechanically harvested, Acta Horticulturae 1043: II European Congress on Chestnut, (2014), 45 - 152. http://dx.doi.org/10.17660/actahortic.2014.1043.19

[18] A. Marucci, D. Monarca, M. Cecchini, A. Colantoni, S. Di Giacinto, A. Cappuccini, The heat stress for workers employed in a dairy farm, Journal of Food, Agriculture \& Environment, 11 (2013), no. 3\&4, 20 - 24.

[19] K. Boubaker, A. Colantoni, E. Allegrini, L. Longo, S. Di Giacinto, D. Monarca, M. Cecchini, A model for musculoskeletal disorder-related fatigue in upper limb manipulation during industrial vegetables sorting, International Journal of Industrial Ergonomics, 44 (2014), 601 - 605. http://dx.doi.org/10.1016/j.ergon.2014.03.005

[20] A. Colantoni, L. Longo, P. Biondi, B. Baciotti, D. Monarca, L. Salvati, K. Boubaker, S.R.S. Cividino, Thermal stress of fruit and vegetables pickers: Temporal analysis of the main indexes by "predict heat strain" model, Contemporary Engineering Sciences, 7 (2014), no. 35, 1881 - 1891. http://dx.doi.org/10.12988/ces.2014.410201

[21] S. Di Giacinto, A. Colantoni, M. Cecchini, D. Monarca, R. Moscetti, R. Massantini, Dairy production in restricted environment and safety for the workers, Industrie Alimentari, 530 (2012), 5-12.

[22] A. Colantoni, A. Marucci, D. Monarca, B. Pagniello, M. Cecchini, R. Bedini, The risk of musculoskeletal disorders due to repetitive movements of upper limbs for workers employed to vegetable grafting, Journal of Food, Agriculture and Environment, 10 (2012), no. 3\&4, 14 - 18. 
[23] M. Cecchini, A. Colantoni, R. Massantini, D. Monarca, The risk of musculoskeletal disorders for workers due to repetitive movements during tomato harvesting, Journal of Agricultural Safety and Health, 16 (2010), 87 - 98. http://dx.doi.org/10.13031/2013.29593

Received: March 30, 2015; Published: October 16, 2015 